\title{
Carative factors in the design development process: towards understanding owner-object detachment and promoting object longevity
}

\author{
Yoon Jung Choi ${ }^{\mathrm{a}}$, J. Stevens ${ }^{\mathrm{b}}$ and C. Brass ${ }^{\mathrm{c}}$ \\ ${ }^{a}$ Innovation Design Engineering, Royal College of Art, London, UK; ${ }^{b}$ Global \\ Innovation Design, Royal College of Art, London, UK; ${ }^{c}$ Department 22, London, UK
}

Yoon Jung Choi, Royal college of Art, Kensington Gore, Kensington, London, SW7

2EU. Tel +44(0) 7881 825808. Email: yoonjung.choi@netwrok.rca.ac.uk

Dr John Stevens, Royal College of Art, Kensington Gore, Kensington, London, SW7 2EU. Tel +44(0)7961 366911. Email: john.stevens@rca.ac.uk

Clare Brass, Department 22, 26 Lambeth High Street, SE11 6AT, Tel +44(0) 7773

7681184. Email: clare@department22.uk

Yoon Jung Choi is $\mathrm{PhD}$ candidate at Royal College of Art. Her PhD focuses on design for owner-object detachment through care practice, for object longevity and environmental benefit. She investigates how 'carative factors' can be translated to the design domain and might offer designers ways to encourage users to emotionally let go of objects, to dispose of them responsibly, or to sustain and extend product lifespan. Her research interest includes design for behaviour change; research method and tools for users in different contexts; participatory design methodologies. Yoon Jung has a MA in Communication design and worked as a structural packaging designer.

Dr John Stevens is Acting Head of the Royal College of Art's Global Innovation Design programme, having joined the RCA in 2013 to help launch this new MA. John's research interests concern the application of design methods to emerging contexts of innovation such as service design, multi-disciplinary design and design management, especially applied to social, cross-cultural and humanitarian innovation. This necessarily encompasses the design of products, interactions and systems. 
Clare Brass is a designer and researcher, focusing on sustainability and circular economy. She is director of Department 22, bringing together young creative talent with businesses sustainability challenges and transforming environmental issues into entrepreneurial solutions. She was head of sustainability at the Design Council before setting up SEED Foundation, working on user-centred environmental challenges such as food, water and waste. She set up SustainRCA at the Royal College of Art leading on a number of commercial and academic research projects focused on the role of design in addressing sustainability and circular economy challenges. 
Carative $^{1}$ factors in the design development process: towards understanding ownerobject detachment and promoting object longevity

Designing for object detachment offers potential for extending an object's lifespan and reducing environmental impact. The philosophy and theory of caregiving in nursing practice may be usefully adapted and applied to the care of possessions. Care-giving behavior towards objects includes maintaining and repairing them, but also letting them go gracefully, and has potential implications for sustainable design.

Little research has explored applying the concept of 'carative factors' to the design process. This study introduces a toolkit based on four motive caring factors and influential factors, and reports on an exploratory workshop, in which participants use the toolkit to generate design concepts. The results suggest that the concept of carative factors has value in the design processes for extending the lifespan of objects, and the toolkit provides better understanding for designers of ownership, disposal and reuse.

Keywords: care practice; object detachment; product longevity; design for sustainable behaviour; lingering attachment

1. Dr Jean Watson $(1985,7)$ uses the term carative to distinguish this important element of clinical practice from the curative practice.

\section{Introduction}

During the $20^{\text {th }}$ century the cultural and economic value of products dramatically changed as the availability and affordability of mass-produced, low cost goods increased in the marketplace (Walker 2006; Gwilt, Fisher, and Young 2015). Most people in the wealthy nations of the world are used to buying and consuming countless products. Often they take no action when they are no longer needed, piling up objects in the back of the closet as they have remaining emotions, to be forgotten, or otherwise throwing them away although they are still perfectly functional. Annually, around 
670,000 tonnes of furniture and 310,000 tonnes of textiles are disposed by householders in the UK although they are still reusable (WRAP 2012). In this climate of consumption, appropriate ways to let go of objects for re-use or responsible disposal seem to have become less important, and many people pay no attention to it. Others face difficulty acting decisively when the relationship with an object nears its end; they experience a kind of emotional attachment to objects which might be attributed to loss aversion (Shu and Peck 2011). Accordingly, users' lack of knowledge, skill and motivation, and the lack of an after-use system do not foster care practice which is known to help extend the life or use of particular objects (Gwilt, Fisher, and Young 2015).

Designers have the power to affect the life cycle of products by influencing user behaviour through related objects and services, and thus create direct impact upon society and environment (Bhamra, Lilley, and Tang 2017), but it is difficult to apply in practice. In many ways, encouraging more sustainable behaviour can be seen as a design problem (Lockton 2013), yet behaviour change presents a challenge for designers.

Product longevity (Chapman 2005, 2010; Evans and Cooper 2010; Van Nes 2010) is recognised as one of the strongest strategies to reduce waste, influence consumption and increase positive environmental impacts. One strategy towards longevity is to increase the durability of the relationship between user and product: designing things to last longer, or extending product lifespan by encouraging repair activities (e.g Chapman 2005, 2010; Evans and Cooper 2010; Ackermann, Mugge, and Schoormans 2018). The other main approach is to decouple the ownership and attachment between the users and products by exploring ways to possess less (e.g Botsman and Rogers 2011), including reuse and sharing by multiple users. Marchand 
$(2003,128)$ defined sustainable users as people who are trying to reduce consumption and are conscious of environmental impacts. Her research revealed that such people wish to "free themselves from any attachment to objects", and that "the notion of liberty, manifested in the choice to possess less and prioritize quality over quantity, was... consistently reiterated detachment toward objects and possession". The respondents strive to have access to things, but not to own them; keeping undue accumulation of goods to a minimum, they tend to practice a certain detachment towards objects they own, to deal with the issue of obsolescence, and they favour the high quality, long lasting. In order to meet the requirement of Marchand's (2003) description of sustainable users and to promote sustainable behaviour, both design strategies need to be equally explored.

In Bruce Sterling's Reboot 11 talk, he sees objects as representing frozen social relationships (as quoted in Schöpfel 2009) as print-outs of those relationships, and urges us to keep three types of things - beautiful things, things with emotional meaning, and tools - and to get rid of the rest. The move towards a circular economy is becoming a core part of the business agenda, emphasising the objective of "closing material loops in an economically attractive way to decouple wealth from resource usage" (Van den Berg and Bakker 2015, 365). This system based model will require a transformation from consumers' ownership to usership (Ellen MacArthur Foundation 2013), thus there is a need for a shared responsibility among all stakeholders and consumers, enabling the return of products for reuse, repair and remanufacturing, as well as collection of waste for recycling (Ghisellini, Cialani, and Ulgiati 2016) for zero-waste circular system (Stahel 2010). For this transition to be possible and sustainable, the bond of ownership between users and objects should be loosened, facilitating 'letting go' and sustainable disposal behaviour. This itself necessitates an understanding of the emotional factors at 
play for users (or owners) towards the end of the product life cycle. Such insights have potential for real environmental impact within a transition towards a circular economy.

Cooper (2005) states that increasing product longevity and access-based consumption (e.g. product-service systems or other sharing models) are two strategies for slowing resource consumption to sustainable levels. In the transition stage to a circular economy, digital society has helped this shift, as users are no longer merely passive consumers but are actively involved as co-creators and providers of resources or services to others. With these new ways of consumption a range of solutions has arisen "to reduce waste and mop up the surplus created by over-production and consumption" (Botsman and Rogers 2011, 11). Particularly, peer-to-peer giving or sharing of goods and services, coordinated through community-based online services, contributes to a circular economic system by reducing resource consumption and waste, and may generate financial profit while decreasing negative environmental impact (Ellen MacArthur Foundation 2013).

As Chapman (2009) states, the sustainability crisis is a behavioural issue, not one simply of technology, production, and volume. This paper explores the idea that care-giving behaviour might promote responsible, timely and appropriate detachment from unwanted possessions, and borrows from models in clinical nursing. We propose that exploring humans' intrinsic care-giving behaviour, and discovering the factors that motivate care-giving behaviour ('carative' factors) may help identify appropriate ways of user-object detachment and to promote re-use, in order to sustain and extend product lifespan.

In nursing practice, care-giving behaviour is as much about maintaining or mending subjects (that is, patients) as it is about ways to "let things go gracefully" (Watson 1985, 7), and "for projecting hope in a shared future" (Jones 2013, 16). 
Tronoto's (1993) definition of 'caring' is everything we do to maintain, repair and sustain a subject (i.e. our body or environment). Applying these concepts to user-object relationships may identify ways useful to designers of influencing attitudes and behaviours around possession and lingering attachment, and around object obsolesce and throwaway attitudes.

This paper begins by discussing care-giving behaviour in relation to object detachment, and selected motivational themes in care theory and nursing practice. Next, influential caring factors under each theme are developed into a set of stimuli for a toolkit to be applied in the design process. The interdisciplinary workshop method was used to examine the application of the toolkit to the idea generation process, in relation to a range of objects. It illustrates the potential usefulness of designers having an understanding of users' relationships with objects nearing their end-of-use, and of obstacles and motivations involved with 'letting go'. We conclude by discussing potential benefits of using the toolkit as part of the designer's idea generation process, and of considering users' emotional detachment from objects in design to facilitate product longevity.

\section{Research Methodology}

In essence, this research entailed the design and evaluation of a set of tools to facilitate idea generation around object ownership and disposal. The designer-researcher was both the creator of the tools and the observer of their use, hence acting in and on the context being investigated, in keeping with an action research methodology (Lewin 1946), which involves understanding both "the process of design itself and developing new design action, artifacts or methods" (Pontis 2010). Research through design focuses on the role of the prototype as an instrument of design knowledge enquiry, which evolves as a means to formulate, develop and validate knowledge (Keyson and 
Bruns 2009).

This study adopts some aspects of grounded theory, that data are gathered from the perceived problem to give it relevance and direction. It is taking an inductive methodology, that researcher develop theory from the data collected as they proceed (Robson 2001), continuously re-framing and re-orienting their research questions and methods to help build theory (Eisenhardt 1989). It goes through multiple stages of data collection and coding (Robson 2001), combined with analysis to help locate and build the research (Glaser and Strauss 1967), and re-plan the next stage of research to probe and investigate the theory (Friedman 2008).

\section{Objects Detachment through Care Practice}

"Humankind as a social totality is brought into the world and sustained by care" (Reich 1995, 319-331). Heidegger used the word 'care' at an abstract, ontological level to describe the basic structure of the human self; he claims that "we are care, and care is what we call the human being" (Heideggar 2005, 225). Care represents one of the most fundamental values of humans to maintain this world, and one of humans' intrinsic behaviours. The caring process aims to sustain and maintain (or enhance) a subject's condition, or where this is not possible, to reduce the pain and distress of the inevitable to "let go peacefully" (Watson 1985, 7).

There are two distinct sustainable behaviours that might be promoted through practices of care in design. First is to establish an emotional bond or attachment between user and product, that together with associated practices of care (i.e. repair or maintaining) can sustain and extend product lifetimes (Chapman 2005; Walker 2006). Second, (according to the nursing perspective), the practice of care is also about graceful ways to let go, for "projecting hope into a shared future" (Jones 2013; 
Mayeroff 1971, 7-12). In order to apply this concept to the design domain, this study adapts Watson's term 'carative', coined in her studies of nursing practice as a contrasting concept to 'curative' practice, the dominant subject of medical discourse. Understanding her concepts and identifying the factors will help to develop the ways to value end-of-use objects and let go (that is dispose of them) respectfully, and appropriately.

Watson's 'carative factors' aim to define the caring process that may help a patient maintain life but also "die a peaceful death" (Watson 1985, 7). In certain nursing practice, caring is a process of understanding patients' quality of life, accepting their condition (Purtilo and Doherty 2010) and respecting their current condition. Caring means aiming to provide comfort (when cure is no longer possible) and find ways of gracefully letting go (Purtilo and Doherty 2010). It is necessary for nurses to understand which factors influence the patients (or family) to decide whether it is time to let go peacefully. Knowing such influential factors will help nurses to make better decisions and deliver care appropriately. We propose that the caring process could be applied in user-object relationships to influence a user's view on an object's value at end-of-use, and that aim to encourage users to preserve the value of the current condition for other hopeful opportunities. Furthermore, Jones (2013) exclaimed good care aims to help the person or things progress in some way to be as independent as possible, yet safe. By integrating these concepts, we explore the opportunities to create caring emotions for the possibility of letting go gracefully, and of detachment from ownership, which may contribute to objects' longevity and provide a new approach to design for sustainable behaviour within the context of product longevity and circular economy.

The experience of caring can 'shape us', and help create order and stability in our own lives (Watson 2007). With caring (and being cared for), it can give meaning to 
our ordinary lives through the depth and value that come with emotion (Mayeroff 1971). In other words, through practice of caring emotions (affection, responsibility, commitment and benevolence) users discover the meaning and beauty of objects, and care action becomes meaningful. According to Marchand $(2003,128)$ sustainable users "make conscious efforts to change their outlook as a means of combating the dependence on unnecessary objects" and "wish to rediscover simple pleasure of being, attain happiness and inner peace through respect for others and the living environment". This resonates with the carative philosophy of 'letting go', and we suggest that care practice could help to respond to their requirement and promote sustainable behaviour, discovering and understanding which factors can motivate such emotion and action may be valuable in promoting user-object detachment and care-giving behaviour.

\section{4 - Motive Caring Themes}

In order to explore the dimensions of caring for one's possessions, this study uses Blustein's four forms of care (Blustein 1991, 121-130; Shaw 2015), namely affection, responsibility, commitment and benevolence (Table 1), and applies them to care-giving behaviour from user-object relationship perspective [Table 1 near here]. The forms of care may not only appear as a single form, but could emerge and function in combination. Translating these principles to design, forms of care and carative factors could help users to recognise an individual object's value and be motivated to preserve its value and let go appropriately.

For designers it is important to design products that 'fit' the emotions of the users, that is, products that elicit the emotions that the user would like to experience (Desmet, Overbeeke, and Tax 2015). Emotions dominate decision making because they trigger and motivate behaviour (Desmet and Hekkert 2007). Niedderer's (2013) research focuses on the impact of design on human relationships, investigating 
mindfulness and emotions as a means to engender mindful interaction and behaviour change through design. Triandis (1977) proposed an integrated model of interpersonal behaviour which includes social factors and emotions in forming intentions.

Accordingly, the caring factors identified can be used to inspire and stimulate designers, as a means to invoke users' caring emotions and behaviour change through design.

They can help to explore ideas, and enable new ways to approach problems of attachment and consumption. One approach, which this research has taken, is to provide an inspiration source in the form of a toolkit for brainstorming and idea generation, which is relevant to influence user behaviour. By using inspirational factors to promote particular emotions we have developed the 'carative factors inspirational cards', which aim to help the 'design for sustainable behaviour' idea generation process. The toolkit will be outlined here to provide background for the workshops.

\section{Identifying Carative Inspirational Factors}

The inspirational factors used to promote the four caring emotions (affection, responsibility, commitment and benevolence) were initially drawn from nursing practice. For example, 'anticipating patient's need' or 'predicting what will happen in the future' are factors that induce nurses' commitment and that lead them to deliver care-giving behaviour. These factors were translated to a user-object context with more applicable phrases for designers, such as 'Let users know how objects want to be treated' or 'Let users know what will happen to the object in the future'. To create a concrete concept, the factors were also abstracted from an ongoing literature review of behaviour change strategies. For example, 'making one's goal public' is a factor recognised to promote commitment (Dolan et al, 2009) and will help to deliver caregiving behaviour. Subsequently, this factor is placed under the commitment theme. 
Then we named the inspirational factors to encourage the four emotions as 'carative factors' as they were originally rooted in nursing practice.

\section{Carative Inspirational Factors Cards: A Toolkit for Sustainable Behaviour}

Having explored the possible link between carative factors and product ownership and disposal, the next phase of the study sought to apply the carative model to the design process. Emerging factors were categorised under four motive themes and developed into a set of stimuli for a toolkit (Figure 1). Forty-three influential factors were found during the initial research have provided direct impact on creating original carative factors for influencing behaviour. [Figure 1 near here]. They are described, illustrated, and grouped into themes for the design processes. The toolkit described here aims to allow designers to explore ideas through inspirational questions, to trigger wider viewpoints within an idea generation process to enable different approaches to the design challenge, and to drive creative solutions for letting go of objects respectfully. It consists of illustrations of described situations, colour coded with different motives and inspirational comments from the initial research (Figure 2). The grey box contains inspirational questions for designers to help the idea generation process. [Figure 2 near here].

The toolkit has been further developed and validated over the following three months via two participatory workshop with six masters level design students (see below), and through several informal conversations with four working designers throughout this period of development, in order to understand how it is being used and how to improve its structure and content. 


\section{Concept-generation Using the Carative Factors Cards Toolkit}

As part of the toolkit development process, an interdisciplinary workshop was run with design students. The aim was twofold: first, to provide a critical research environment enabling the identification and examination of the carative factors, and the development of an original design; second, to develop a design-led process to produce case-specific design knowledge which addresses the concept of letting things go. Being used during the idea generation stage, the toolkit may give inspiration to designers and help them to explore the field of possibilities (Lockton 2013), and confirmation of this was sought through feedback and discussion with participants after the workshop.

Three distinct user types were represented in the toolkit to help participants' idea development. Each type is distinguished by the interval length between attitude and behaviour, namely attentive users (narrow gap), shortcut users (medium gap), and careless users (far gap). During the workshop, the focus was on generating a large number of 'unrealistic' ideas, so the quality of the ideas has not been assessed formally. However, possibilities and viability of the concepts are discussed at the end of each study. It is difficult to assess formally the 'usefulness' of any idea generation method: in practice, they are often used in contexts where there can be no comparable control group (Lockton 2013). However, in this case, the workshop was intended to investigate how participants used the toolkits, whether they found it beneficial, and which aspects were well understood and which were not, and this was evaluated through discussion and observation. 


\section{Design Workshop: Ink Cartridges, A Chair and A Pair of Running Shoes}

The workshop was held at the Royal College of Art (RCA) involving six participants for idea generation and discussion. RCA design students were recruited internally, and were asked to bring examples of end-of-use objects they retain at home. This provided the opportunity to discuss barriers to object detachment and to consider whether and how this might be problematic (Figure 3). [Figure 3 near here] Later they were asked to redesign the objects, or to create a service or system using the toolkit, then to join in a discussion to evaluate the toolkit.

Table 2 describes five distinct obstacles that became apparent during the discussion (Table 2 near here). Written notes and video recordings were used to collect data during the studies, which permitted re-reading and replaying the workshop and discussion, and helped eliminate personal bias and preconceptions (Miles and Huberman 1984). Based on the discussion, each group selected objects to discuss and explore how best to deal with it.

The participants were asked to draw end-of-use objects, which they have let go happily and decisively, that is with a positive sense of purpose or appropriateness. Drawn examples were a laptop, jacket and boots. The participants reported that this process helped them to think about motivational factors at play and gave an opportunity to reflect on the carative factors, developed from the previous stage. The positive factors participants listed were 'knowing its destination', 'knowing a person in need', 'getting rewards or payment' and 'receiving appreciation'. Identifying and discussing such obstacles helped the participants become more aware of the issues around ownership, disposal and end-of-use objects. Having an understanding of barriers to desired behaviours is likely to improve the success of designed outcomes towards behaviour change in reaching the target behaviour (Fogg 2009). 
In the final part of the workshop, the six participants were divided into three pairs, and asked to choose an object (or image of an object) from the collection of examples they had brought. Group 1 selected an unopened ink cartridge to explore ideas around how to best deal with it. The ink cartridge had been kept because it was new and unused although the printer was given away. Group 2 was interested to explore ideas around furniture, especially a chair. The owner kept it because it might be useful in the future. Group 3 chose end-of-use shoes, which were kept at home because the owner couldn't find the appropriate place to give them away.

\section{The Concepts}

In the next part of the session, the participants stayed in pairs and generated design concepts using carative factor inspirational cards, focusing on the ideas of relinquishing things for a closed-loop material process. Participants were allowed to choose user types they wished to explore for each theme. The pairs used a method similar to the thinkaloud discussion method (Ericsson and Simon 1984, chapter 5), explaining and discussing their thoughts during the concept generation session (Lockton 2013). The idea generation session in the workshop lasted 2 hours; 15 minute for each idea exercise on each caring theme.

Twenty-five design concepts were generated using the toolkit and the concepts are summarised according to the four motives of carative factors framework. Figure 4 represents a selection of ideas from the workshop. [Figure 4 near here]. Some ideas for the end-of-use ink cartridges already existed on the market - such as reward users for taking back cartridges to the seller - however there are some interesting concepts in Table 3. [Supplemental Material]. Group 1 mainly focused on instilling responsibility or 
commitment among users. None of concepts were generated through the theme of affection. However, in this case, the users had a low level of lingering affection towards the ink cartridge. Therefore group 1 had difficulty generating ideas in this theme. Group 2 generated fifteen concepts around an end-of-use object, a chair. They developed ideas on each of the four themes. Although the burden of responsibility might be regarded as the main reason for keeping furniture, having lingering regret to prepare for the unexpected possible needs was another reason for failing to let go/keep ownership of it. All three other factors were also used to generate concepts and nine concepts have been generated through the cards. According to this group, obstacles to detachment for furniture owners may vary according to their personal experiences, and responsibility is not the only factor to consider but all of four themes are relevant. Group 3 chose an endof-use pair of sports shoes (trainers), they interestingly produced one solid idea by using four themes together. Although each theme of cards was given out at a different time, they built upon the one idea by using all four themes.

Most of ideas generated focussed on passing it onto another user, or returning it to the manufacturer. Some of the concepts the participants generated were redesigning the whole products, or focusing on improving the services and system at the end-of-use of the objects for appropriate disposal.

\section{Reflection}

Because of the limited time available, not all of the forty-three carative inspirational factors have been considered during the idea generation session. One group started with one factor and worked through the session before moving onto the next themes, while others picked up multiple inspirational factors interesting to them. Additionally, one group used the cards to explore as many ideas as possible, whereas others built upon 
one solid idea by using the cards. In almost all cases, participants requested more time to continue working at the end of the session. This engagement possibly means the toolkit helped to inspire them to explore ideas in certain ways. The workshop process also provided an opportunity to rethink about the theme 'Affection'. The aim of the motivational theme was to let designers explore ways to enable graceful letting go of end-of use objects with high lingering affection. However, one participant stated that such a situation would not encourage her to share their personal story with another user and would hesitate to let go. Another participant brought in an object, which was an unwanted gift from a family member, stating that she could not imagine letting it go to a stranger. Considering the participants' responses it might be a more viable approach to strengthen the object attachment through design (rather than through the object detachment approach) to extend their lifespan. Furthermore, in many cases, owners find secure places to give away their objects when they experience lingering affection, reassured that they are reducing the chances of it being thrown away. From this, the affective theme does not appear to be a useful factor in the idea generation practice. However, design for object detachment through carative factors is more useful where users have lingering regret or low lingering attachment to objects, such as being aware of an object's value but lacking an appropriate place to pass it on. Participants tend to use 'threatening' or 'constraint' factors when they explore the ideas with 'careless users'. More ideas were generated when they were exploring the 'attentive users' or 'shortcut users",

According to participants, "comments from interviewees written in the toolkits helped designers to think from the user's perspective", "the toolkit enabled openness to new design ideas" and "I strongly engaged with the issues and design concept, would like to adopt the toolkit for my future project again". The findings of this study have 
provided an insight into the potential value to designers of an awareness of how carative factors may help address the issues of product obsolescence and longevity.

\section{Discussion}

In the transition stage to a circular economy, it is important for designers to understand users' ambivalent engagement with the end-of-use objects, which potentially leads to wasteful attitudes. How users deal with end-of-use objects could have a huge impact by reducing functional waste and enabling the recirculation of material for a zero-waste circular system (Stahel 2010). Many of the leading industries have started to adopt a circular economy approach by adopting circular systems and design processes to facilitate product reuse, recycling and cascading. In order to establish core strategies such as the reuse, repair, remanufacture and recycling of technical cycles, the design process needs to consider the life cycle of end-of-use objects; there are, however, few supporting tools available for designers to use. Accordingly, Jones $(2003,255)$, in discussing tools she developed for an early-stage eco-innovation workshop, suggested that "tools are more likely to be adopted in industry if they can be integrated nonintrusively into existing design process". In this sense, carative factors as an inspirational tool could provide a better understanding for designers to explore an 'object detachment' approach during the idea-generation process.

Design for sustainable behaviour is increasingly recognised in the development of new products and services (Lilley 2005). In the field of design research for behaviour change, not all the methods or frameworks produced are available for designers to use in their practice. Some researchers have developed 'design for behaviour change' models based on user research studies around specific kind of behaviour. They have been well described and presented in an illustrated form (e.g. Tang 2010), but there are 
limitations to the direct application and use of these in the idea generation phase. However, Lockton's (2013) Design with Intent toolkit does provide a minimal format: the toolkit aims to explore a broader sense of behaviour change rather than being focused on the end cycle of product use. The carative inspirational toolkit specifically aims to influence users' disposal behaviour rather than the wider characteristics of behaviour change.

A spectrum of control or power of distribution (Lilley 2005; Zachrisson et al. 2011; Bhamra et al. 2011) are included in many behaviour change approaches, which are making a substantial contribution to the field of design for sustainable behaviour. However, people's behaviour is also affected by a more conscious and considered understanding of our needs, desires and priorities (Dolan et al, 2009). Recognising these various influences is also crucial, given the complex environment in which people make decisions (Dolan et al, 2009). A mindful design approach seeks to enable behaviour change through attitude change, based on mindful awareness and reflection. It is about providing internal motivational elements which enable conscious decision-making and commitment as an essential basis for attitude change, and subsequently for lasting behaviour change (Neidderer 2013). While carative inspiration factors take a holistic approach in provoking caring emotions in people (responsibility, commitment and benevolence) through design, which helps their decision-making processes for sustainable disposal behaviour, they could also make a contribution to the field of design for sustainable behaviour. At this stage it is difficult to judge the usefulness of the toolkit by comparing it with other available toolkits, as they are designed for many different purposes. However, this research aims to contribute to the research field of design for sustainable behaviour by providing a better understanding of ownership and 
sustainable disposal behaviour for designers and establishing strategic design approaches to promote product longevity in the design development processes.

It is not yet possible to conclude whether the ideas designed using the toolkit would have an impact on the environment, or whether these ideas could have been generated by other methods. However, responses were sufficiently positive to encourage further work towards a tool that may enable designers to influence consumers' emotional response to end-of-use products, and that could influence more sustainable behaviour through decisive, appropriate disposal. This study has provided designers with a better understanding of relations between users and end-of-use objects. It also demonstrates that introducing the notion of carative factors can offer designers the possibility of enabling object detachment to achieve longevity.

\section{Conclusion}

This study is a part of the toolkit development process to explore concepts via an action research cycle of planning, acting, observing and reflecting processes. These studies suggest that designers may benefit from a deeper understanding of end-of-use scenarios, particularly users' lingering attachment to objects and the effect of this on the obsolescence of objects, and how to design longer-lasting objects through carative factors to lessen the distress around the disposal of objects: that is, to let go gracefully.

Applying metaphor to an ill-defined problem can help to structure design problems, increase designers' knowledge of a particular design situation and stimulate design creativity (Casakin 2007). Exploring the concept of carative behaviour and borrowing relevant caring factors from nursing practice as a metaphor has had this effect among this few workshop participants, which could encourage sustainable behaviour in users. 
However, the most important test of an idea generation method is whether it is found to be useful by its users - whether they choose to use it, or continue to use it (Lockton 2013). The toolkit needs to be tested further in terms of its usability and its benefits in an industrial context or a real-world setting. To this end, the toolkit will be available online from June 2018, to be further tested in designers' own design briefs. Design for object detachment for a longer-lasting product is a relatively underexplored research area; further work may extend it using it in a real-life industry setting with a wide range of object types such as clothing or mobile phones, which are consumed on a massive scale and very often disposed of without care.

Acknowledgments

The authors are indebted to the workshop participants for their time and invaluable feedback.

\section{References}

Ackermann, Laura, Ruth Mugge, and Jan Schoormans. 2018. "Consumers' Perspective on Product Care: An Exploratory Study of Motivators, Ability Factors, and Triggers." Journal of Cleaner Production 183: 380-391

Anderson, K. 2009. "Ethnographic Research: A Key to Strategy" Harvard Business Review, March 2009. Accessed 2 March. https://hbr.org/2009/03/ethnographicresearch-a-key-to-strategy.

Blustein, J. 1991. Care and commitment: Taking the personal point of view. New York: Oxford University Press.

Bhamra, Tracy, Debra Lilley, and Tang Tang. 2011. "Design for Sustainable Behaviour: Using Products to Change Consumer Behaviour.” The Design Journal 14 (4): 427-445.

Botsman, R., and R. Rogers. 2011. What's Mine is Yours. How Collaborative Consumption is Changing the Way We Live. London: HarperCollins. 
Casakin, H.P., 2007. "Metaphors in Design Problem Solving: Implication for Creativity." International journal of Design 2 (2): 21- 33.

Chapman, J. 2005. Emotionally Durable Design: Objects, Experiences and Empathy. Earthscan.

Chapman, J. 2009. “Design for (Emotional) Durability.” Design Issues 25 (4): 29-35. Chapman, J. 2010. "Subject/Object Relationships and Emotionally Durable Design.” In Longer Lasting Products: Alternatives to the Throwaway Society, edited by T. Cooper, 61-76. Surrey: Gower.

Cooper, T. 2005. "Slower Consumption Reflection on Product Life Spans and the Throwaway Society.” Journal of Industrial Ecology 9 (1-2): 51- 67.

Davis, J. B., and R. McMaster. 2007. "The individual in mainstream health economics: A case of Persona Non-grata." Health Care Analysis. 15 (3): 195-210. In "Care and Commitment in Ethical Consumption: An Exploration of the AttitudeBehaviour Gap", by Shaw, D., R. McMaster, and T. Newholm, Journal of Business Ethic. Advance online publication. doi:10.1007/s10551-014-2442-y.

Defra (Department for Environment, Food \& Rural Affairs). 2011. Moment of Change as Opportunities for Influencing Behaviour. London, UK: Government. Accessed 26 April 2015. https://orca.cf.ac.uk/43453/1/MomentsofChangeEV0506FinalReportNov2011\% $282 \% 29$.pdf.

Desmet, P., and P. Hekkert. 2007. "Framework of Product Experience." International Journal of Design 1 (1): 57-66.

Desmet, Pieter, Kees Overbeeke, and Stefan Tax. 2015. "Designing Product with Added Emotional Value: Development and Application of An Approach for Research through Design.” The Design Journal 4 (1): 32-47.

Dolan, Paul, Michael Hallsworth, David Halpern, Dominic King, Robert Metcalfe, and Ivaylo Vlaev. 2009. Mindspace - Influencing Behaviour through Public Policy. London, UK: Cabinet office \& Institute for Government.

Eisenhardt,K. M.1989. "Building Theories from Case Study Research.” The Academy of Management Review 14(4): 532-550.

Ellen MacArthur Foundation. 2013. Towards the Circular Economy Vol. 2:

Opportunities for the Consumer Goods Sector. Accessed 23 December 2016. https://www.ellenmacarthurfoundation.org/publications/towards-the-circulareconomy-vol-2-opportunities-for-the-consumer-goods-sector. 
Ericsson, K., and H. Simon. 1984. Protocol Analysis and Verbal Reports as Data. $2^{\text {nd }}$ ed. MIT Press: Cambridge.

Ethics of Care. 2011. "Interview With Chris Gastmans." Ethics of Care. Accessed 20 January 2016. http://ethicsofcare.org/chris-gastmans/.

Evans, S., and T. Cooper. 2010. Consumer Influences on Product Life-Spans. In Longer Lasting Products: Alternatives to the Throwaway Society, edited by T. Cooper, 319-350. Surrey: Gower.

Fogg, B. J. 2009. “A Behavior Model for Persuasive Design.” In Proceedings of the 4th International Conference on Persuasive Technology. doi:10.1145/1541948.1541999.

Fogg, B. J., and J. Hreha. 2010. "Behavior Wizard: A Method for Matching Target Behaviors With Solutions." In Proceedings of the 5th International Conference on Persuasive Technology 117-131. doi: 10.1007/978-3-642-13226-1_13.

Friedman, K. 2008. "Research into, by and for Design." Journal of Visual Art Practice 7(2) $153-160$.

Ghisellini, Patrizia, Catia Cialani, and Sergio Ulgiati. 2016. "A Review on Circular Economy: The Expected Transition to A Balanced Interplay of Enviornmental and Economic Systems." Journal of Clear Production 114(7) 11-32.

Glaser, B. G and A. L. Strauss. 1967. The Discovery of Grounded Theory: Strategies for Qualitative Research. Aldine de Gruyter, New York, NY

Gwilt, Alison, Jackie Leaver, Mark Fisher, and Gordon young. 2015. "Understanding the Caring Practice of Users." In Proceedings of the Product Lifetimes and The Environment Conference, no. 1: 125-129.

Heideggar, M. 2005. Being and Time. Commentary on Heidegger's Being and Time. $7^{\text {th }}$ Ed. Blackwell Publishing.

Jones, E. A. 2003. "Eco-Innovation: Tool to Facilitate Early-Stage Workshop.” PhD diss., Brunel University.

Jones, P. H. 2013. Designing for Care. Rosenfeld Media: Brooklyn, New York.

Keyson, D. V and M, Bruns. 2009. "Empirical Research Through Design” In Proceedings of The International Association of Societies of Design Research. 4548-4557.

Kirschen, M. 2001. “The Want of Caring.” Accessed 30 December 2015. http://infed.org/mobi/caring-in-education/. 
Lewin, K. 1946. “Action Research And Minority Problems.” Journal of Social Issues, 2(4), 34-46.

Lilley, D. 2007 "Designing for Bahaviour Change: Reducing the Social Impacts of Product Use through Design,” PhD diss., Loughborough University.

Lockton, D. 2013. "Design with Intent; A design Pattern Toolkit for Environmental \& Social Behaviour Change.” PhD diss., Brunel University.

Marchand, A. 2003. "Sustainable Users and the World of Objects Design and Consumerism.” In Eternally Yours: Time in Design, edited by E. Van Hinte, 102-131. Rotterdam.

Mayeroff, M. 1971. On Caring. New York: Harper \& Row.

Miles, M and Huberman A.M. 1984. "Drawing valid meaning from qualitative data: Toward a shared craft." Educational Researcher ,13 (5): 20-30. Accessed 23 February 2018.

http://journals.sagepub.com/doi/abs/10.3102/0013189X013005020

Niedderer, K. 2013. "Mindful Design as A Driver for Social Behaviour Change." In proceedings of Consilience and Innovation in Design: $5^{\text {th }}$ International Congress of International association of Societies of Design Research. 45614571.

Pontis, 2010 “Types and Approaches of Design Research” May 2010 May. Accessed 16 April 2017. https://sheilapontis.wordpress.com/2010/11/05/types-andapproaches-of-design-research/

Purtilo, R and Doherty R. 2010. Ethical Dimensions in the Health Professions. Sanuders.

Reich, W. eds. 1995. Encyclopedia of Bioethics. 5 vols. New York: Simon \& Schuster Macmillan.

Robson, C. 2011. Real World Research: A Resource for Social Scientist and Practitioner-Researcher. Blackwell, Ocford.

Shaw, D., R. McMaster, and T. Newholm. 2015. "Care and Commitment in Ethical Consumption: An Exploration of the Attitude-Behaviour Gap.” Journal of Business Ethic doi:10.1007/s10551-014-2442-y.

Shu, S.B and Joann P. 2011. "Psychological Ownership and Affective Reaction: Emotional Attachment Process Variable And the Endowment Effect." Journal of Consumer Psychology. 21(2011) 439-452.

Stahel, W. R. 2010. The Performance Economy. Basingstoke: Palgrave Macmillan. 
Sterling, B. 2009. Reboot 11 Speech. Transcripted by S. Schöpfel. 25 June 2011.

Accessed 20 January 2016. https://www.wired.com/2011/02/transcript-ofreboot-11-speech-by-bruce-sterling-25-6-2009/

Tang, T. 2010 “Towards Sustainable Use: Design Behaviour Intervention to Reduce Household Environmental Impact.” PhD diss., Loughborough University. Triandis, H. C. 1977. “Interpersonal Behavior”. Monterey, CA: Brooks/ Cole. In "Design for Sustainable Behaviour to Change Consumer Behaviour", edited by Bhamra,T., D. Lilley, and T. Tang. 2015. The Design Journal, 14 (4): 427-445.

Tronto, J. C. 1993. "Moral Boundaries: A Political Argument for An Ethic of Care.” In "Care and Commitment in Ethical Consumption: An Exploration of the Attitude-Behaviour Gap”, edited by Shaw, D., R. McMaster, and T. Newholm. 2015. Journal of Business Ethic, doi:10.1007/s10551-014-2442-y.

Van den Berg, M. R., and C.A. Bakker. 2015. "A Product Design Framework for Circular Economy." In Proceedings of the Product Lifetimes and the Environment Conference No. 1: 365-379. Accessed May 052016. http://www.plateconference.org/product-design-framework-circular-economy/.

Van Nes, N. 2010. "Understanding Replacement Behaviour and Exploring Design Solutions." In Longer Lasting Products: Alternatives to the Throwaway Society, edited by T. Cooper, 107-132. Surrey: Gower.

Walker, S. 2006 Sustainable by Design: Explorations in Theory and Practice. London: Earthscan.

Watson, J. 1985. Nursing: Human Science and Human Care, A Theory of Nursing. Jones \& Bartlett Learning.

Watson, J. 2007. “Watson's Theory of Human Caring and Subjective Living Experience: Carative Factors.” Danish Clinical Nursing Journal. 20 (3): 21-27. WRAP (Waste and Resource Action Programme). 2012. Composition and Re-use Potential of Household Bulky Waste in the UK. Accessed 19 April 2015. http://www.wrap.org.uk/sites/files/wrap/UK\%20bulky\%20waste\%20summary.p df.

Zchrisson, J., and C. Boks (2011) "Using a Guide to Select Design Strategies for Behaviour Change; Theory vs Practice." In Proceeding of EcoDesign 2011 " $7^{\text {th }}$ International Symposium on Environmentally Conscious Design and Invers Manufacturing. 
Table 1. 4-Motive caring themes, descriptions and examples of carative inspirational factors.

Table 2. Participants' comments and five distinctive obstacles.

Table 3. Ideas generated through the workshop. (Supplemental Material)

Figure 1. 4 - Motive caring themes and carative inspirational factors.

Figure 2. A description of an early version card.

Figure 3. Participants are discussing the obstacles.

Figure 4. A selection of ideas from the workshop. 
Table 1. 4-Motive caring themes, descriptions and examples of carative inspirational factors

\section{Affection}

Aim: When the users have affection towards end-of-use objects then they tend to value the object and in caring for this way, let go gracefully when the time comes.

Description: The primary level to create value of things is through affection and loving forms of care. With this type of relationship people are naturally inclined to help and give care. In this study Affection factors' emphasis is on encouraging letting go to pass the objects to a 'meaningful place' rather than evoking affective response from users through the object's design. (Desmet and Hekkert 2007).

Examples of inspirational factors: Knowing the progress of an object once given, Knowing it is a secure and trustworthy destination.

\section{Responsibility}

Aim: When users have a responsibility for the end-of-use object then users tend to maintain the value of the object and let go respectfully.

Description: Through responsibility and duty form of care, people act because it is the right thing to do (Kirschen 2001).

Examples of inspirational factors: Getting rewards for my behaviour, Objects made of living thing, Send a reminder, Seeing other people 'doing the right thing'.

\section{Commitment}

Aim: When users commit to certain activities because of environmental concern, then users tend to maintain the value of the object and let go respectfully.

Description: The ethic of care role dominates, so if not delivered some might feel guilty (Kirschen 2001). People are not forced to act but act voluntarily. The behaviour contains certain social norms and is socially acceptable with shared intention. The commitment to care has longevity and consistency (Blustein 1991, Davis and McMaster 2007). Commitment refers to the willingness to spend time and energy for something and do it for a long time (Fogg and Hrena 2010).

Examples of inspirational factors: Being watched by other people, Getting feedback on users' behaviour, Knowing what will happen in the future, Providing a long-term plan.

\section{Benevolence}

Aim: When users' environment encourages their benevolence, they tend to maintain the value of the object and let go respectfully.

Description: Whether to act or not depends on the person's context or mood and the situated environmental influences (Blustein 1991).

Examples of inspirational factors: Passing objects to other people are easy, Availability and acceptability. 
Table 2. Participants' comments and five distinctive obstacles

\begin{tabular}{|c|c|c|}
\hline Objects & Comments & Obstacle \\
\hline $\begin{array}{l}\text { Ink } \\
\text { cartridge }\end{array}$ & $\begin{array}{l}\text { "I felt uncomfortable throwing the cartridge } \\
\text { away due to environmental concern, but I } \\
\text { don't know how to find another user with a } \\
\text { compatible printer." }\end{array}$ & $\begin{array}{l}\text { Lack of knowledge and/or availability of } \\
\text { suitable services or systems for disposal. }\end{array}$ \\
\hline $\begin{array}{l}\text { Projection } \\
\text { screen, } \\
\text { chair, } \\
\text { Mattresses }\end{array}$ & "It is too bulky to deal with it." & $\begin{array}{l}\text { Big size, heavy weight and difficulty of } \\
\text { disassembly. }\end{array}$ \\
\hline $\begin{array}{l}\text { Projection } \\
\text { screen, chair }\end{array}$ & "I might need it later." & Lingering attachment for practical reasons. \\
\hline $\begin{array}{l}\text { A pair of } \\
\text { trainers }\end{array}$ & $\begin{array}{l}\text { "It is out of fashion and unhygienic to give } \\
\text { them away. But I do not want to donate the } \\
\text { object to charity, because there is a high } \\
\text { chance of the shoes being thrown away." }\end{array}$ & Having difficulty finding a new recipient. \\
\hline $\begin{array}{l}\text { Spaghetti- } \\
\text { measuring } \\
\text { ring }\end{array}$ & $\begin{array}{l}\text { "It was an unwanted gift from an } \\
\text { acquaintance." }\end{array}$ & $\begin{array}{l}\text { Having lingering attachment to object for } \\
\text { emotional reasons. }\end{array}$ \\
\hline
\end{tabular}

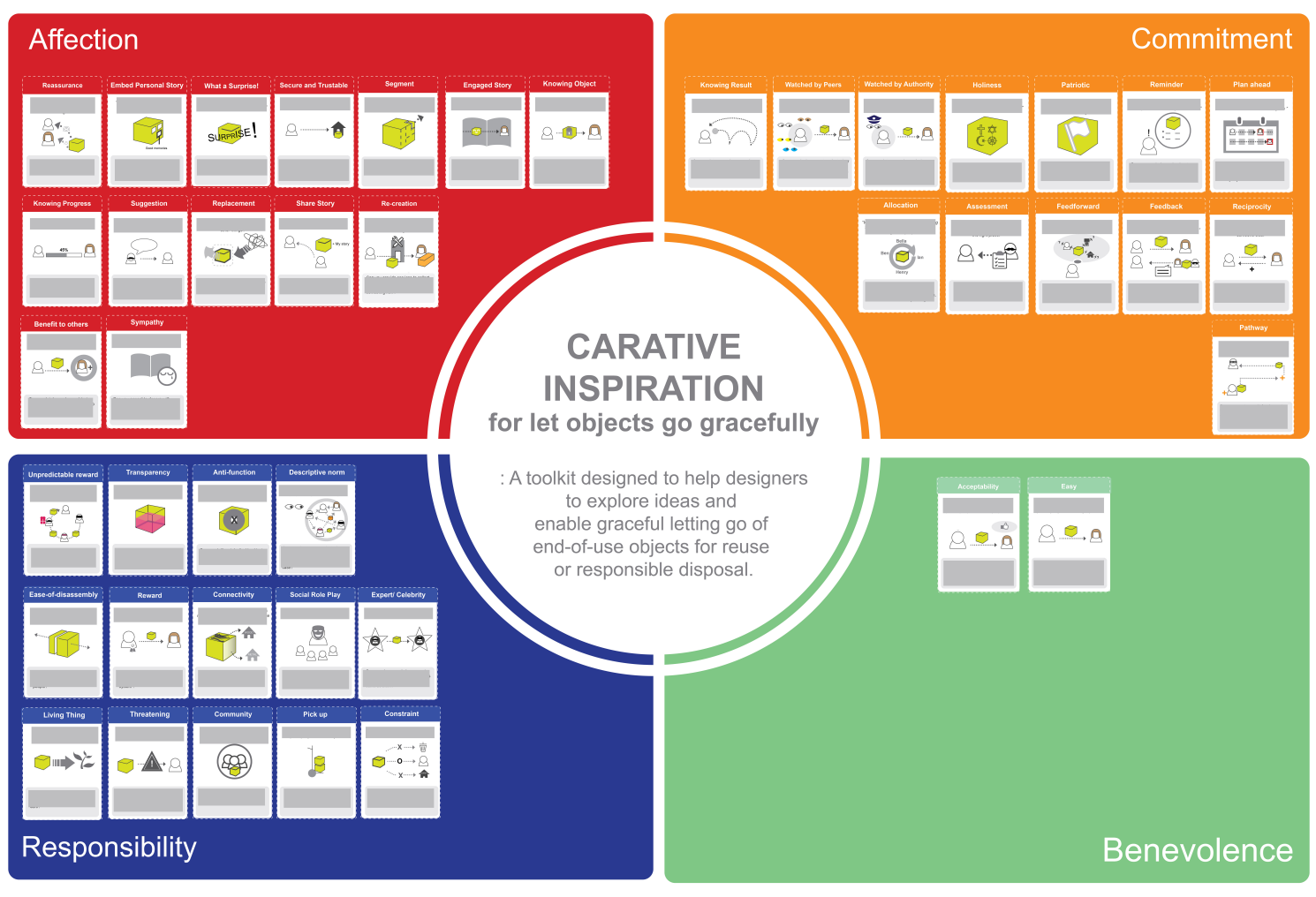



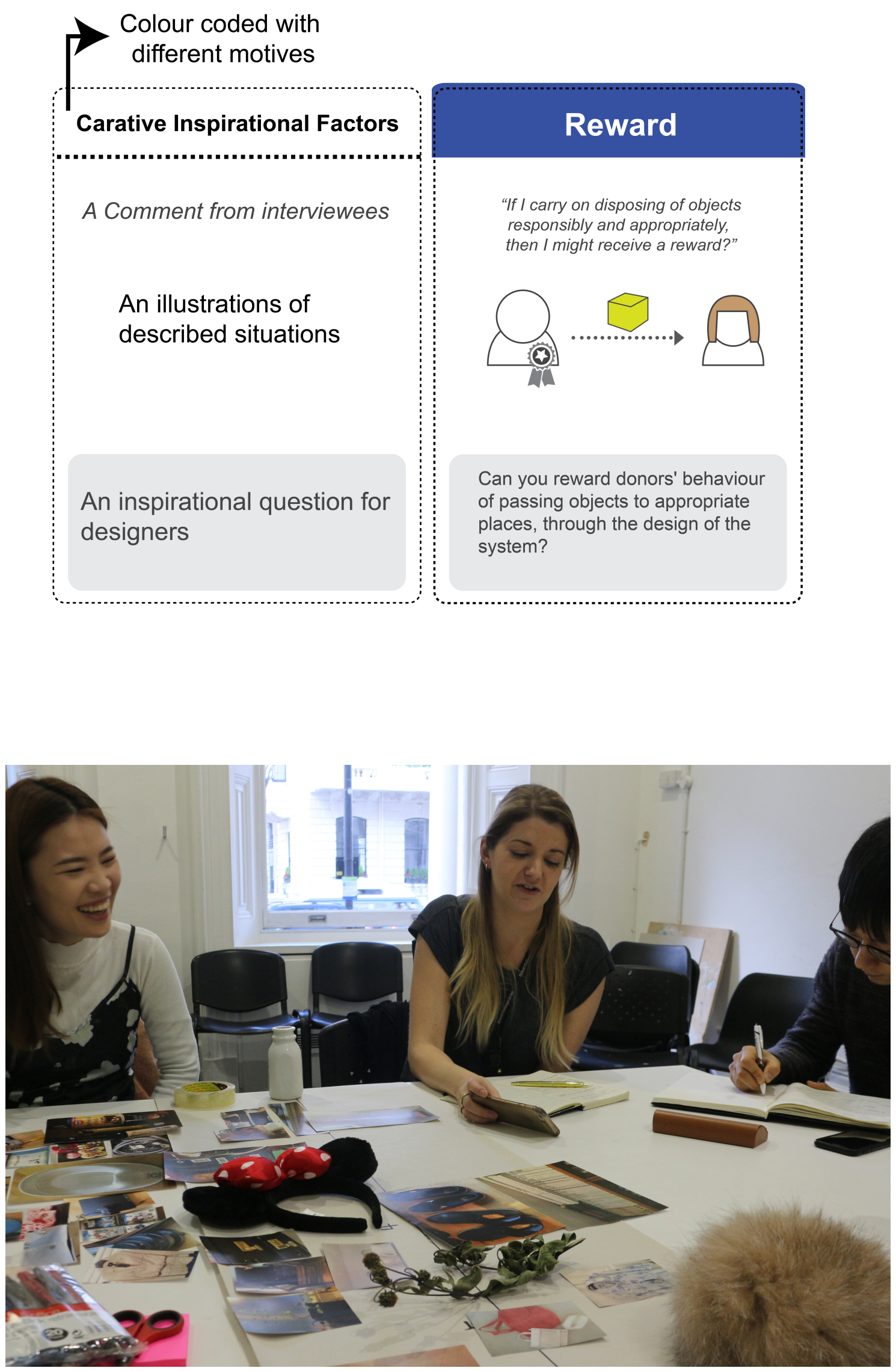


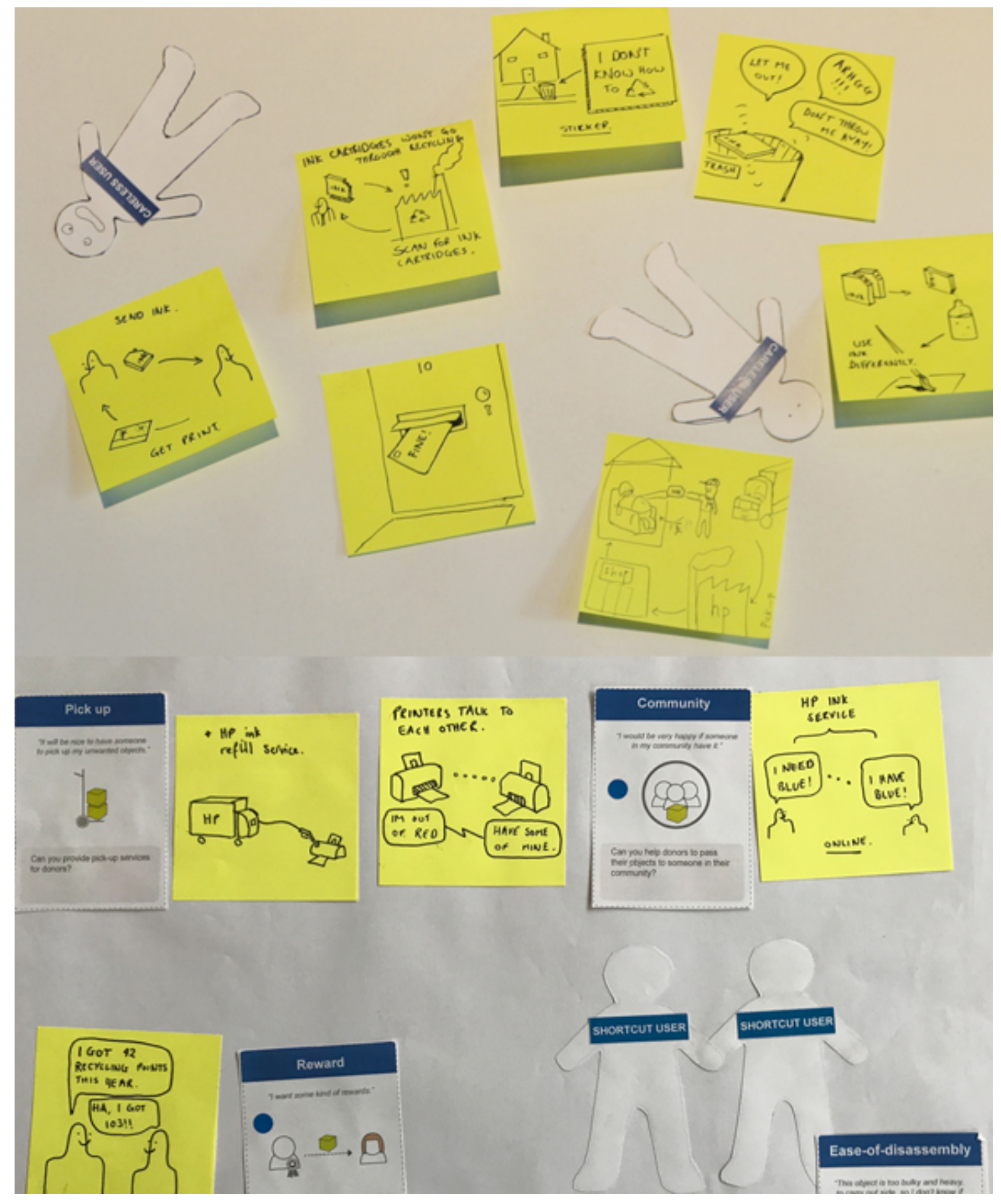

